\title{
AN EFFECTIVE DATABASE MANAGEMENT OF THE URBAN UNDERGROUND FACILITIES AND TOPOGRAPHIC INFORMATION
}

\author{
Žilvinas STANKEVIČIUSS ${ }^{1}$, Dominykas ŠLIKAS ${ }^{2}$, Darius POPOVAS ${ }^{3}$ \\ Institute of Geodesy, Vilnius Gediminas Technical University, Sauletekio al. 11, \\ LT-10223 Vilnius, Lithuania \\ E-mails: ${ }^{1}$ z.stankevicius@gis-centras.lt; ${ }^{2}$ dominykas.slikas@vgtu.lt(corresponding author); \\ ${ }^{3}$ darius.popovas@vgtu.lt
}

Received 19 October 2015; accepted 03 November 2015

\begin{abstract}
In developed countries the most accurate and reliable spatial data (M 1:500-1:1000) are extensively used. The same spatial object could be inscribed into separate systems: utilities companies have some systems, municipality collected catalogues of CAD data, separately developed real estate map. The same spatial objects are repeated and reiterated, unreasonable costs are incurred for their storage, the customers find it complicated to determine and select the best and appropriate spatial data required just for their own needs.

This article suggests the solution of the problem. Authors have introduced the idea to compose and develop information system specialized for topography and infrastructure subsequently to be merged and coordinated. The model for data storage, data provision to the customers and service activities is defined. The available electronic services for the spatial data are described as advantageous for implementation on topographic maps, for inspection and monitoring of construction projects, for the issue of permits of excavation works and for the other activities.
\end{abstract}

Keywords: topographic information system, permit for excavation works, technical project, design plan, engineering network drawing, electronic service.

\section{Introduction}

There is a lack of the public spatial information about position of the underground engineering infrastructure (Statistics electrical incidents). Meanwhile, almost all the available engineering infrastructure is spread out in public institutions. Due to the inadequate scope, errors and uneven structure of the topographic maps stored at the municipalities, the following difficulties constantly appear:

- The specialists of the municipality are not able to use the most relevant topographic data and make decisions efficiently;

- Experts dealing with the projects on territorial planning and construction work are unable to apply topographic data for strategic projects and to make alternative decisions;

- Land surveyors have no possibility to precisely determine the special terms and conditions for land and forest usage;

- The preparation of the projects takes longer, therefore the possibility of making mistakes significantly increases and that could lead to an unexpected additional expenses during the process of construction;

- Investors and enterprises are not able to have an independent evaluation of the existing engineering infrastructure;

- Frequent damages of the underground network occur while carrying out the excavation work;

- It is rather complicated to eliminate damages in the underground infrastructure.

Because of the reasons mentioned above the financially strong enterprises developed the autonomous infrastructure data storage systems. Nowadays, information about infrastructure objects (mainly engineering networks) are stored or duplicated on private databases and could not be accessible for public use. Among these enterprises are the following:

- a group of enterprises operating the engineering infrastructure networks;

- several municipalities; 
- railway companies;

- real estate cadastre data handling companies.

The above mentioned spatial databases differ one from another and are not complete or fully reliable. In most cases, the geodetic control/as-built surveys, performed by a small municipal enterprises engaged in construction, are lost. The geodetic control/as-built surveys, performed by a private operator engaged in construction of the networks, in most cases are not accessible for planers and designers. The objects of engineering infrastructure (networks, streets/roads) entered to the cadastral databases lose part of the information contained on the geodetic control/as-built surveys.

\section{Description of the problem}

Topographic maps compiled in Lithuania within the period of 1960-2000 contained all the accessible parametric information on the infrastructure networks; it was practically impossible to obtain quickly any additional information in the operating enterprises. Thus, the system mentioned above was based on the insignificant diversity of the network types, the non-existence of the computer technology and a small amount of the codified parametric information on the networks in the operating enterprises (the files were stored at the enterprises, approximate schemes were compiled).

Meanwhile, together with the spread of computer technologies, enterprises methodically initiated the storage of parametric information about the infrastructure networks. The amounts of parametric information are significantly bigger compared to conventional topographical plans. The majority of the parametric network information (previously it was unknown, as well as there was no possibility to show it on topographic maps) is useful for designing or it is necessary for enterprises responsible for the maintenance of the networks (in such cases as specified voltage, pressure or isolation of the main waterways and pipelines).

It is a big challenge to find out a compromise between a designer and the needs of responsible enterprises in terms of the content of the information about engineering networks. The geodetic technical regulations present the results of geodetic measurements but they face the same problem as well. The directive on 'INSPIRE' describes the possible structure of the spatial data of engineering networks, where the attributes and classifications could be forecasted (INSPIRE 2012).
It is not possible to compile a valuable national spatial data infrastructure (SDI) without the available large scale maps (most accurate and most extensively applied spatial data of topography and infrastructure) and without having the accessible strategy of data collection. Other publications indicate that such data could be used as a part of SDI (Kyrkjeeide, Lillethun 2004; van der Molen 2005; Quak, de Vriese 2006).

The updating of the large scale topographic maps during the period from 1960 to 1992 in Eastern European countries was usually performed by scratching off the changed or extinct elements in the analog maps and drawing with an ink the new ones. For example, in Lithuania such maps were stored in the centralized archives of the State Engineering Research Institute (SERI). Generally, the repository and storage of the archives was used, because in cases of necessity it was economically disadvantageous to undertake geodetic measurements of the objects once again, the location of which was already previously determined in the territory; and because it could be rather complicated to identify the spatial position of the underground engineering networks after the trenches were filled up. Approximately in 1992 under the Governmental Order the functions of the owner regarding the National Estate Fund were prescribed to the municipalities, 1:500-1:2000 scale topographic maps were attributed there as well. In 1992 SERI was closed and the archives were transferred to the municipalities. The municipalities acted under their own discretion and competence for eight years. The digital technologies in maps production during that period rapidly developed.

There were prepared documents where coding structure for large scale topographic maps was described. For example, specifications of the Integrated Geo-Reference Information Systems (InGIS, Lithuania). Nevertheless the structure of electronic data and technology of spatial data upgrading was not mentioned in any available document or regulation (Stankevičius, Paršeliūnas 2005).

The current situation does not allow to modernize processes of plans usage (Stankevičius et al. 2010); create electronic services and forces duplicating of the same spatial objects in the databases of different institutions (Stankevičius 2008).

The models of the cost sharing among the partners could be various. The part of the coverage in the partnership is diverse, e.g., GEOVEKST and 
GBKN projects include private enterprises maintaining the networks (Høstmark 2002; Mardal, Lillethun 2005; Norge digital 2008), FOT project is oriented towards the accumulation of the large scale topographic data and involve the institutions of municipalities, railways, and the cooperation of the institutions responsible for the national topographic and cadastral measurements (Kort \& Matrikelstyrelsen). If compared with the legislation in Lithuania, the greatest difference is that in those projects as well as in the majority of the other countries (Kok 2005) the following requirements are applied, i.e., the enterprises maintaining the engineering networks are obliged to accumulate and provide the special data on spatial objects (IMKL 2.2. 2014); partners usually accumulate 1:500-1:2000 scale topographic data (the error on position is allowed up to $3 \mathrm{~m}$ in case of the aero photo when the objects are in the shade) and topographic data (located on the ground, slopes, trees, fences, electric cables, poles, manholes and similar types, installation cabinets in public places; data are collected for the first time and periodically upgraded photogrammetrically according to the centralized notices of the procurements); the accumulated data are reliable and suitable for the usage (e.g. GBKN project within the three months period complemented the deficiencies noted); the data are also updated in the various public administrative sectors of the municipality and by applying the compiled technical maps when directly measuring the locality (Specification FOT4 2009). It is also necessary to estimate the fact that in other countries all requirements mentioned above were achieved as the result of the long-lasting partnership processes.

\section{Topographic maps used for planning}

Technical regulations determining the constructional processes as well as the regulations on preparation of the detailed maps cover the requirement indicating that all maps have to be of a certain period of validity. Thus, there is a tendency to prolong the period of validity for the maps (from 1 to 5 years in Lithuania). The extension of the validity of the topographic maps is related to the efforts of project designers to use the same map for the longest possible period of time. The excavation work schedule has to be agreed together with the owners of the underground infrastructure and communication networks.

The constructional processes regarding designing and planning are based on the date when the topographic maps were checked with the operators of the engineering networks; the processes of land use and property registration are based on the archives of the large scale topographic maps. Therefore, in the archives of the municipalities only the fragments of the mutually disintegrated topographic maps are mostly stored, which could not be applied directly in the processes of planning and designing. The material available in the archives is regularly combined into a single set of the spatial objects in the topographic maps, the content of which is monitored by the experts of the enterprises maintaining engineering networks; as a result it is used only to solve one task and after that they are lost.

The analysis of the situation implies that the processes of planning, designing, construction and property registration are not coordinated with the accumulation and presentation of the topographic and infrastructure data used for these processes. Generally speaking, some legal acts specify the order how topographic maps have to be collected; the other legal acts restrict the usage of the accumulated maps for the infrastructure development. Thus, there is no possibility for the accrued and regularly adjusted topographic maps, developed for the particular area, to be considered as the reliable ones and practically applicable within the unlimited period of time allowing designing and constructing of the infrastructure. The funds invested into the accumulation, administration and adjustment of the topographic maps usually turn to be the unjustified expenditures.

\section{Information system of topography and infrastructure}

The analysis of situation revealed that the unanimous and conventionally agreed information system of topography and infrastructure (TIIS) should be created for the upgrading and adjustment of the spatial data functioning under the principles of cooperation (Fig. 1). The structure of the spatial data of TIIS has to be organized under the guidance and basis of GIS and it has to be open for the expansion possibilities. Thus, it could open the possibilities for the majority of the enterprises maintaining engineering networks and institutions to apply TIIS.

The initial information sources should be used to update TIIS, namely topographic maps before designing and before filing up the trenches with communication cables, after the object has been built. Besides that all the spatial objects of the infrastructure are 
collected irrespectively from the current or future form of ownership. The spatial objects of the infrastructure are given the unique references for the contacts with the departmental information; the information regarding the constructor of the object is also attached there.

The upgrading and adjustment of TIIS is considered to be the constantly ongoing production process for integrating the fragments of the spatial data. To ensure the financial continuity and vitality it is suggested to establish partnerships in public and private sectors.

The spatial data compiled during the project of cooperation would be useful for:

- revision of the maps and delivery to the households, businesses, experts and operators of engineering networks;

- speeding up to provide the approved topographic information for the processes of planning and designing;

- reduced demand for technical equipment and software for servers and working places;

- constant and independent (from the particular organization or the owner of the equipment) updating of the spatial data;

- disappearing demand to duplicate the spatial data in the governmental information systems;

- more accurate decisions of the pre-designing processes, faster processes of planning and designing;

- ensured spatial background regarding the related services of the infrastructure expansion.

\section{Methodology of the data bases updating}

Updating the data bases at TIIS has to be operated under the principleof the decomposed special data, namely when a surveyor at his working place integrates new spatial data into the fragments of the spatial database and when the automatic means and measures register the attribute information of the spatial data as the updating information (CUI); then the public service officers at the enterprises and municipalities review the material on Internet, verify and check maps working on-line; an officer at the TIIS integrates the fragment of the spatial data according to CUI. The major work related to the integration has to be performed at the working place of a surveyor; the employees of the municipality are not obliged for editing procedures on the spatial data adjustment.

The fundamentals for the application of CUI technology are the following: the transfer of the fragment (FSD) of the spatial database to a surveyor and the receiving of it from the surveyor has to be made in the open standard language GML; tracing changesX update information and recording the attributive data into FSD at the working place of a surveyor. The concept of the applied technology is presented in Figure 2.

Processes of spatial data editing are described in Figure 3 (at scale 1:500). That is the expansion applied at any market by a surveyor of the manufacturing enterprise, which when operating within the environment of the manufacturer, continues the observation

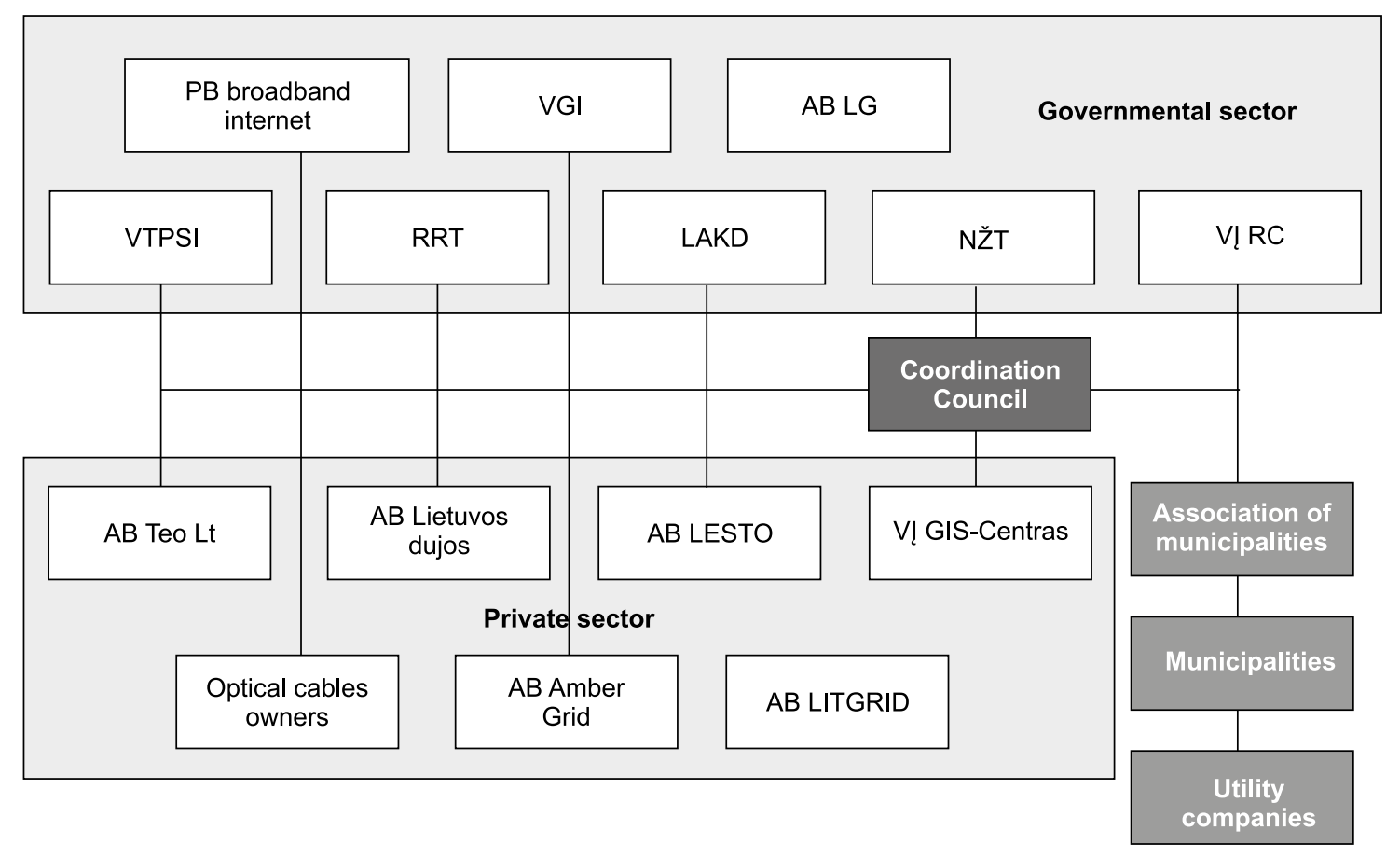

Fig. 1. TIIS cooperation and financing model 
of the activities of the surveyor. Hereinafter, the most popular cases of the spatial data editing are presented based on the analysis of the management of the archival spatial database (ArcMap, manufacturer ESRI) and FSD editing (AutoCAD Civil, manufacturer Autodesk).

\section{Conclusions}

In order to have in the country freely accessible, reliable and suitable for various construction procedures spatial data, it is necessary:

- To develop the information system of topography and infrastructure (TIIS).
- To allocate responsibility when submitting a particular type of objects for the constructional procedures to be performed.

- To distribute the financial funds for the maintenance of TIIS among the owners of information systems.

- To divide the work regarding the integration of the new data for TIIS when applying the changesX updating information.

\section{Acknowledgements}

This work was supported by Ministry of Agriculture of the Republic of Lithuania under Grant

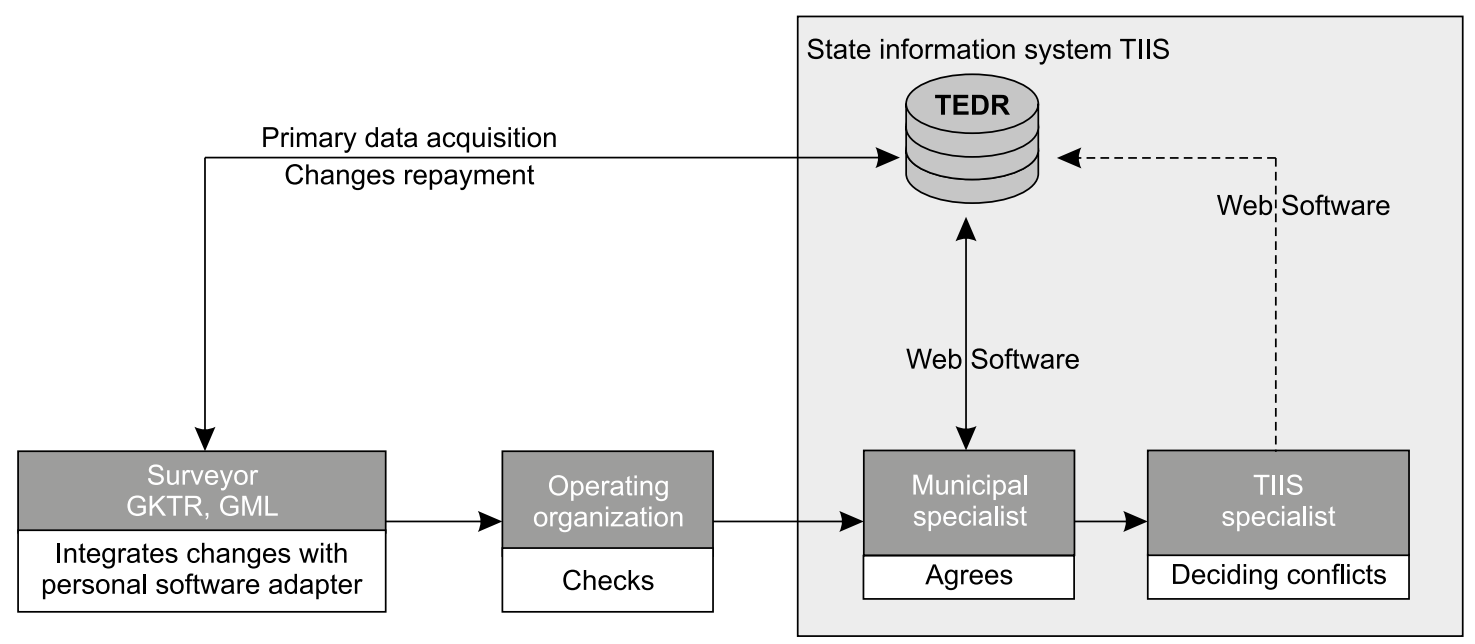

Fig. 2. Sequence of adjustment the change in information

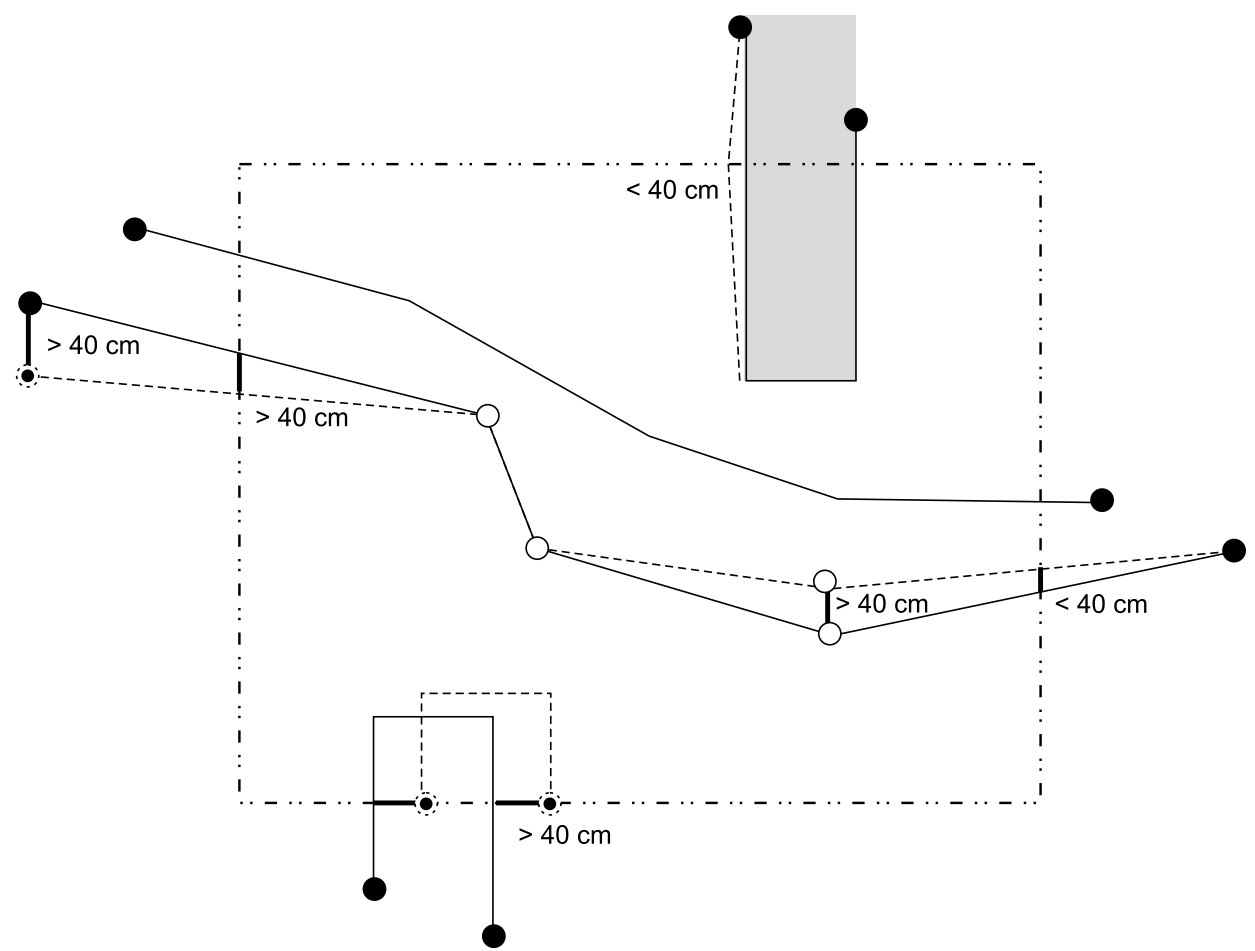

Fig. 3. Updating procedure of TIIS database 
MT-14-18/11258. The authors gratefully acknowledge this support.

\section{References}

Høstmark, A. K. S. 2002. GEOVEKST - a Norwegian program for cost sharing in production, updating and administration of geographic data, in FIG XXII International Congress, 19-26 April 2002, Washington, USA.

IMKL2.2. 2014. Data Model. Agentshap voor Geografische Informatie Vlaanderen [online], [cited 02 October 2015]. Available from Internet: https://www.agiv.be/producten/klip/ meer-over/technische-documentatie/technische-documentatie-imkl

INSPIRE. 2012. Infrastructure for spatial information in Europe D2.8.III.6 Data Specification on TUtility and governmental services Y - Draft Guidelines [online], [cited 02 October 2015]. Available from Internet: http://inspire.ec.europa.eu/ documents/Data_Specifications/INSPIRE_DataSpecification_LU_v3.0rc3.pdf

Kok, B. 2005. Partnership building is a crucial element of the Dutch NSDI, in FIG Working Week 2005 and GSDI-8, 16-21 April 2005, Cairo, Egypt.

Kyrkjeeide, K.; Lillethun, A. 2004. AREALIS - Norwegian environmental spatial data infrastructure programme. Norwegian Mapping Authority.

Mardal, L.; Lillethun, A. 2005. Reference data specification through GEOVEKST - a Norwegian national programme for reference data cooperation. Geovekst.

Norge digital. 2008. General terms and conditions for Norway digital co-operation.

Quak, W.; de Vriese, M. 2006. Building a harmonized base model for geo-information in the Netherlands, in The 25th Urban Data Management Symposium, May 15-17 2006, Aalborg, Denmark, 4.13-4.24.

Specification FOT4. 2009. GeoDanmark [online], [cited 02 October 2015]. Available from Internet: http://www.geodanmark. $\mathrm{dk} /$ Materiale/files/FOTspecifikation/FOT4+specifikation_ UK.pdf

Stankevičius, Ž. 2008. Feasibility study of united national cartographical model, in The 7th International conference 'Environmental engineering': selected papers, 22-23 May 2008, Vilnius, Lithuania. Vol. 3. Vilnius: Technika, 1483-1487.
Stankevičius, Ž.; Beconytè, G.; Kalantaitè, A. 2010. Automation of update of digital national geo-reference databases. Technological and economic development of economy, Baltic Journal on Sustainability 16(2): 254-265. http://dx.doi.org/10.3846/tede.2010.16

Stankevičius, Ž.; Paršeliūnas, E. 2005. Standardisation of large scale geo-data sets, in The $6^{\text {th }}$ International Conference 'Environmental Engineering': selected papers, 26-27 May 2005, Vilnius, Lietuva. Vol. 2. Vilnius: Technika, 1008-1013.

Statistics electrical incidents in Alberta, Canada, January 1 to December 31, 2012 [online], [cited 02 October 2015]. Available from Internet: http://www.municipalaffairs.alberta.ca/ documents/ss/STANDATA/electrical/2012-IncidentStatisticalReport.pdf

van der Molen, P. 2005. Authentic registers and good governance, in FIG Working Week 2005 and GSDI-8, 16-21 April 2005, Cairo, Egypt.

Žilvinas STANKEVIČIUS received his $\mathrm{PhD}$ in Measurement Engineering from Vilnius Gediminas Technical University in 2000. He is currently working at the National Centre of Remote Sensing and Geoinformatics TGIS-Centras. Žilvinas Stankevičius is the author of more than 20 scientific articles and two textbooks. Research interests include spatial data infrastructures, large scale topographic information management and visualization, sustainable development and spatial analysis in $3 \mathrm{D}$ space.

Dominykas ŠLIKAS completed his PhD in Geodesy and Cartography, Vilnius Gediminas Technical University, Lithuania, in 2013. Presently he is a researcher in the Institute of Geodesy at Vilnius Gediminas Technical University. His current research interests include global navigation satellite system (GNSS) and terrestrial laser scanning.

Darius POPOVAS completed his PhD in Geodesy, Vilnius Gediminas Technical University, Lithuania, in 2011. Presently he is an assistant professor in Geodesy and Cadastre department at Vilnius Gediminas Technical University. His research interests include EarthXs gravity field, global navigation satellite system (GNSS) and terrestrial laser scanning. 